Article

\title{
The Effect of COVID-19 on the Efficiency of Intercity Bus Operation: The Case of Chungnam
}

\author{
Wonchul Kim ${ }^{1}$ and Sung Hyo Hong ${ }^{2, *(\mathbb{D})}$ \\ 1 Department of Spatial \& Environmental Planning, Chungnam Institute, Gongju-si 32589, Korea; \\ iwonchul@cni.re.kr \\ 2 Economics Department, Kongju National University, Chungnam 32588, Korea \\ * Correspondence: shong11@kongju.ac.kr
}

Citation: Kim, W.; Hong, S.H. The Effect of COVID-19 on the Efficiency of Intercity Bus Operation: The Case of Chungnam. Sustainability 2021, 13, 5958. https://doi.org/10.3390/ su13115958

Academic Editor: Guido Perboli

Received: 21 April 2021

Accepted: 24 May 2021

Published: 25 May 2021

Publisher's Note: MDPI stays neutral with regard to jurisdictional claims in published maps and institutional affiliations.

Copyright: (C) 2021 by the authors. Licensee MDPI, Basel, Switzerland. This article is an open access article distributed under the terms and conditions of the Creative Commons Attribution (CC BY) license (https:/ / creativecommons.org/licenses/by/ $4.0 /)$.

\begin{abstract}
This paper estimates the efficiency of operating intercity bus lines in Chungnam province over the period 2017-2020, and then empirically analyzes the determinants of the efficiency. In particular, it evaluates to what extent the efficiency in 2020 decreased due to COVID-19 and which characteristics of lines (length of a line, frequency of operation, whether a line operates via highways and includes the capital region or not) affected the efficiency during the pandemic through a tobit model. The empirical results show that the efficiency in the operation of intercity bus lines in Chungnam was higher in 2018 and 2019 compared to 2017, but dropped in 2020 by $15.8 \%$. It appears that the efficiency is higher when a line operates more frequently and covers a longer distance, but the efficiency increases at a decreasing rate as the operating distance becomes longer. In addition, the difference in the efficiency according to operating distance due to COVID-19 seems to be statistically significant. Given that intercity bus lines are heavily dependent upon a (local) government's financial support and the amount of this support needs to reflect the degree to which the efficiency has decreased due to COVID-19 as an external shock, it is important to precisely estimate the magnitude of the efficiency reduction from both a policy and academic standpoint.
\end{abstract}

Keywords: COVID-19; intercity bus; efficiency; data envelopment analysis; tobit model

\section{Introduction}

Infectious diseases such as COVID-19 have brought about many changes in daily life. The transportation sector has also undergone several changes, and most of all, a significant decrease in traffic has occurred. According to Jang et al. [1], passenger transportation performance from the first of March 2020, compared to the third week of January, decreased by $66 \%$ for intercity buses, $69 \%$ for express buses, $32 \%$ for taxis, $32 \%$ for city buses, and $38 \%$ for subways. Support from the (local) government for the operation of intercity buses causes much debate, considering its equity in terms of support for the transportation vulnerable, including low-income families, and its efficiency in terms of the opportunity costs of the support budget.

Many studies have reported the impacts of COVID-19. Sobieralski [2] argued that the airline industry seemed to experience a reduction in the capacity of major carriers by 60 to $80 \%$. For a Swedish case, Jenelius and Cebecauer [3] measured the decrease in public transit ridership, with the largest reduction, 60\%, in Stockholm. According to the Global Carbon Project [4], carbon emissions from road transportation are down globally by $10 \%$ for the year.

The number of intercity bus users has decreased every year due to the expanding supply of private cars and the inconvenience of transferring. The decrease in the number of intercity bus passengers leads to management difficulties for intercity bus carriers, and the aggravated management difficulties continue to weaken the willingness to improve intercity bus services. As a way to alleviate such problems, support for financial losses incurred in operating intercity buses is provided based on Article 50 (financial support) 
of the Passenger Transport Service Act. The method of financial support is prescribed as "financial support" by recommendation rather than mandate, and the scope of financial support is stipulated within the budget that can be tolerated by local governments in charge of transportation companies. The operating loss of intercity bus carriers caused by a decrease in bus passengers is also aggravated when driving in areas where there are no users or when the line is heavily curved. The decrease in bus passengers may be considered an external factor that cannot be solved by the voluntary efforts of bus companies, but the improvement of efficiency of the line through efficiency analysis can be considered an internal factor that bus companies can control. For intercity bus companies facing the worst business conditions due to the plunge in the number of bus passengers caused by strengthened social distancing measures in response to the COVID-19 pandemic, the process of reviewing the efficiency of line operation, which is an internal control factor, is important in the sense of promoting the soundness of intercity bus companies after the pandemic is resolved.

This paper estimates the operational efficiency of all intercity bus lines in Chungnam province from 2017 to 2020 through data envelopment analysis and empirically analyzes the factors that affect it. In particular, it analyzes to what extent the efficiency has decreased in 2020 due to COVID-19, and which characteristics of lines, such as the length of lines, frequency in operation, use of highways, and inclusion of the capital region, influence the efficiency through a tobit model.

Although many preceding studies have analyzed the efficiency of public transportation, very few have empirically estimated changes in the operational efficiency of intercity buses due to external shocks such as infectious diseases. In particular, as intercity buses constitute one of the welfare policies for the transportation vulnerable, the support for those who supply them is integral, and a more accurate estimation of efficiency reduction is required to derive the appropriate size of support. In this regard, the empirical results of this paper would have policy implications.

The following section discusses theoretical arguments and methods of empirical analysis suggested in earlier studies on the operational efficiency of buses. Section 3 describes the data and the basic statistics of variables included in the regression analysis. Section 4 explains the results of empirical analyses based on the estimation of regression equations. The last section concludes the paper by discussing its policy implications.

\section{Theoretical Background and Empirical Analysis Model}

\subsection{Theoretical Background}

Although the bus transportation business is a private-led business sector, it is subject to financial assistance for operating losses by the government because it is a necessity good for everyday life that has the nature of public goods, with the government controlling the bus fare, and therefore efficient operation is indispensable. In this regard, many researchers have studied the operational efficiency of bus lines, and in general, data envelopment analysis (DEA) was used as the method of analysis.

First of all, Sung et al. [5] used DEA to evaluate the efficiency of the city bus quasipublic operation system in Busan Metropolitan City. The input variables for the evaluation were the mileage, elapsed time, the number of vehicles, dispatch interval, and the number of operations. The number of passengers, number of transfer passengers, and transportation revenue were used as calculation variables. To improve the efficiency of 205 lines, the study concluded that it is necessary to reduce the number of lines, and the analysis revealed that the factors that significantly affected the operational efficiency index were, in order of importance, elapsed time, number of passengers, and number of transfer passengers.

Lee and Na [6] analyzed the efficiency of bus lines in large cities with the implementation of the bus quasi-public operation system based on the situation in Gwangju Metropolitan City. The number of passengers, number or transfer passengers, and transportation revenue were used as the calculation factors of the DEA analysis model. Mileage, driving time, number of vehicles, dispatch interval, and number of operations were used as 
input factors. In the case of rapid transit, line efficiency increased after the implementation of the bus quasi-public operation system, while arterial and branch lines showed less efficiency. The increase in inefficiency was interpreted as a reason to increase convenience for citizens by increasing the number of operations and operation time even though the efficiency had decreased slightly after the quasi-public operation system was conducted.

Oh and Kim [7] utilized DEA to analyze the efficiency of the city bus transportation business in Seoul. The input factors used for data envelopment analysis were labor, vehicles, oil, and maintenance. Urban buses and seats-only buses were utilized as outputs. The efficiency score was assessed by tobit regression analysis techniques, and the ratio of maintenance personnel, the average length of the lines, the number of lines, and mileage per vehicle were applied as independent variables. As a result of the analysis, reducing the proportion of maintenance personnel and increasing the operating ratio of seats-only buses were proposed as ways to increase efficiency.

There are some studies using stochastic frontier models for the efficiency of bus companies. For example, de Jong and Cheung [8] for a case from the Netherlands, Kumbhakar and Bhattacharyya [9] for an Indian case, Matas and Raymond [10] for a Spanish case, and Sakano et al. [11] for a US case utilized non-DEA methods.

Cui et al. [12] analyzed the impact of COVID-19 on China's transport sectors based on the CGE model with a decomposition analysis approach. They specified multiple shocks of COVID-19-the supply-side shocks that raised the protective cost and reduced the production efficiency, and the demand-side shocks that reduced the demand of households and production sectors for transportation. Loske [13] evaluated the impact of COVID19 on transport volume for a German case. Hu and Chen [14] examined socioeconomic disparities in the impact of COVID-19 on ridership in Chicago using Bayesian structural time series model.

There are several papers that evaluated the effect of COVID-19 on transportation using DEA. Peoples et al. [15] showed that social distancing during the COVID-19 pandemic has weakened the performance of airline companies and argued that efficient operations do not guarantee the avoidance of productivity decline during a recession. Pereira and Soares de Mello [16] evaluated the change in the operational efficiency of Brazilian airlines caused by lower demand during the COVID-19 pandemic. Their findings indicate that the company with a better mix of aircraft models has leverage on efficiency response. $\mathrm{Li}$ et al. [17] explored how exogenous environmental factors affect bus transport operations and found significant impact from an analysis using a tobit model.

To our knowledge, this is the first paper that evaluates the effect of COVID-19 on intercity bus operation in Korea using big data. The empirical analysis is based on all 2508 lines that were operated by all the five bus companies in Chungnam province from 2017 to 2020.

\subsection{Empirical Analysis Model}

In data envelopment analysis, efficiency is measured as a relative concept of production frontier and can be expressed as follows under the assumption of convexity and free disposability:

$$
\begin{aligned}
& \max \mathrm{z}=\mathrm{uy}_{\mathrm{j}} \\
& \mathrm{vx}_{\mathrm{j}}=1 \\
& -\mathrm{v} X+\mathrm{uY} \leq 0 \\
& \mathrm{v} \geq 0 \\
& \mathrm{u} \geq 0
\end{aligned}
$$

where $\mathrm{j}$, as a decision-making unit, corresponds to the individual line of the intercity bus operation company, while $\mathrm{x}$ and $\mathrm{y}$ correspond to the input vector and output vector, respectively. The parameter $\mathrm{z}$ is a weighted output. Additionally, $\mathrm{u}$ and $\mathrm{v}$ belong to a vector of weights for output and input, respectively. There are two models of relative efficiency based on changes in production, namely invariance of remuneration [18] and variability [19]. In this paper, the input factors to measure the efficiency of intercity bus 
companies include the number of days of operation on the line, the total annual mileage, and the number of vehicles on the line, and the calculation factors are sales and profits. The measurement of efficiency is based on the input factors and assumes that the production change represents an invariant remuneration for the scale.

The regression equation of the tobit model for analyzing factors affecting the efficiency of individual lines measured by data envelopment analysis is defined as follows:

$E_{j t}=\beta_{0}+\sum_{k=1}^{5} \gamma_{k}$ firm $_{j k}+\sum_{t=2017}^{2020} \mu_{t}$ year $_{t}+\beta_{1}$ daily $_{j t}+\beta_{2}$ distance $_{j t}+\beta_{3}$ highway $_{j t}+\beta_{4}$ Seoul $_{j t}+\varepsilon_{j t}$

where $E_{j t}$ represents the efficiency of line $j$ in year $t$. firm $j k$ is a dummy variable representing a bus company operating line $j$. This controls the difference in efficiency between bus companies due to their unique characteristics. year t represents a dummy variable for the year, and the estimated value of the coefficients of the dummy variables for 2020 is expected to have a value less than zero due to COVID-19 under the hypothesis of this paper. daily $y_{j t}$ represents the frequency in operation, and distance ${ }_{j t}$ indicates the operating distance. highway $_{j t}$ represents whether the line operates via the highway, and Seoul ${ }_{j t}$ indicates whether the line operates via the capital region. $\varepsilon_{j t}$ represents a common error term. To estimate the effect of these variables on the efficiency due to COVID-19, dummy variables representing 2020 and cross-terms between these variables are analyzed by adding them to the regression Formula (1). The data used in the empirical analysis of this paper correspond to the line-year panel data because it includes annual figures for individual lines. Therefore, the random effect model is further analyzed to improve the efficiency of the estimation coefficients.

\section{Data and Variable}

\subsection{Data}

There are five intercity bus companies operating in Chungnam. The total number of routes decreased from 730 in 2018 to 515 in 2020. This decrease was mainly caused by the drop in the loading rate and thus the rise in the number of routes with deficit. The intercity bus companies who operate these routes are financially supported by the local government, because the majority of users of the routes are the transportation vulnerable in rural areas. However, the share of routes with deficit rose from $72.2 \%$ to $85.5 \%$ over the period, and this aggravates the financial burden on a local government. Thus, policy tools that enhance the efficiency of the intercity bus operation are required.

The data used for the empirical analysis of this paper include a database stored in the Chungnam Bus Company Cost Analysis System developed by Chungnam in 2016. Five intercity bus companies (Geumnam Express, Chungnam Express, Hanyang Express, Samheung Express, Jungbu Express), which receive guidance, supervision, and financial support from Chungnam, enter information into the system on a daily basis (cloud-based server operation). They enter their accounting information (approved line names, mileage, bus terminal names, stopover names, number of operations, transportation revenue, etc.) by storing revenue (fare revenue) and expenditure information (transportation cost) for lines authorized by Chungnam. The intercity bus companies use the Chungnam Bus Company Cost Analysis System to analyze their accounting information, while Chungnam uses it to manage and analyze profit and loss information for each approved line.

The number of lines per year was 695 in 2017, 730 in 2018, 568 in 2019, and 515 in 2020, with a total of 2508 observations being included in the analysis. There are 1172 lines which existed for only one year in the analysis period of 2017-2020, while other lines operated for all four years, corresponding to an unbalanced panel.

\subsection{Variable}

Table 1 shows the basic statistics of the variables included in the empirical analysis of this paper. The average efficiency of lines over the entire analysis period of 2017-2020 is 0.463 , and by year it rose from 0.467 in 2017 to 0.486 in 2018 and 0.514 in 2019, but dropped significantly to 0.370 in 2020, suggesting that there was a decrease in intercity 
bus passengers due to COVID-19 and a resulting reduction in sales and profits. The frequency in operation for each line is 6.4 times, ranging widely from a minimum of 1 time to a maximum of 104 times. The standard deviation is 8.4 times, which shows the large difference between lines. The operating distance of lines is on average $148.7 \mathrm{~km}$ one-way. Among all lines, 77.9 percent of the lines use highways, and their average toll is 8927 won. Meanwhile, the proportion of lines via the capital region is 60.7 percent.

Table 1. Basic statistics of variables.

\begin{tabular}{|c|c|c|c|c|}
\hline Variable & Average & Std. Dev. & Minimum & Maximum \\
\hline Efficiency overall & 0.463 & 0.343 & 0.003 & 1 \\
\hline Efficiency in $2017(n=695)$ & 0.467 & 0.332 & 0.008 & 1 \\
\hline Efficiency in $2018(n=730)$ & 0.486 & 0.344 & 0.003 & 1 \\
\hline Efficiency in $2019(n=568)$ & 0.514 & 0.357 & 0.007 & 1 \\
\hline Efficiency in $2020(n=515)$ & 0.370 & 0.320 & 0.005 & 1 \\
\hline Frequency in operation (number of one-way trips per day) & 6.4 & 8.4 & 1 & 104 \\
\hline Operating distance (in meters) & 148.7 & 62.9 & 17.5 & 416.8 \\
\hline $\begin{array}{l}\text { Whether the line is via highway ( } 1 \text { if via highway, } \\
0 \text { otherwise) }\end{array}$ & 0.779 & 0.415 & 0 & 1 \\
\hline $\begin{array}{l}\text { Highway toll (only for lines via highway) (Korean Won; only } \\
\text { for lines via highway) }\end{array}$ & 8927 & 4947 & 1600 & 27,900 \\
\hline $\begin{array}{c}\text { Whether the line is via capital region (1 if via capital region, } \\
0 \text { otherwise) }\end{array}$ & 0.607 & 0.488 & 0 & 1 \\
\hline
\end{tabular}

\section{Empirical Results and Discussions}

Table 2 shows the results of the tobit model estimation for factors affecting efficiency. Column (1) includes variables indicating whether the line uses highways or not, while column (2) includes highway tolls as an explanatory variable. Statistically significant differences are shown in operational efficiency among intercity bus companies, suggesting that companies' unique characteristics, such as management capabilities, do play a role, although this could not be further analyzed by explanatory variables due to data limitations. The annual efficiency was relatively high in 2018 and 2019, compared to 2017, as shown in the basic statistics in Table 1, but fell by 15.8\% in 2020.

As the frequency in operation increases, the cost of driving will increase, but an increase in the number of operations means an improvement in services, such as a decrease in the average waiting time for users. If the increase in the number of riders through service improvements exceeds the increase in costs due to an increase in the number of operations, this will increase efficiency because it increases profits along with revenues. The regression analysis results demonstrate this possibility empirically.

The longer a line is, the more efficient it is, but the additional increase in efficiency following the longer operating distance appears to gradually decrease. If the increase in operating distances for individual routes is not very significant, the number of vehicles and drivers on that route will not change. This corresponds to a fixed cost, and the longer the applied distance, the lower the average cost per unit distance up to a certain level. On the contrary, for a given long-distance line, more vehicles and drivers would be required when it is operated by several short-distance lines. Then, the bus company has to pay money in maintaining the extra vehicles and in employing the extra drivers, even though the total distance of operation is the same. The analysis shows that an economy of this size appears to be present. 
Table 2. Tobit model results for factors affecting the efficiency of intercity bus operations.

\begin{tabular}{|c|c|c|c|}
\hline & (1) & (2) & (3) \\
\hline \multicolumn{4}{|l|}{ Intercity bus company } \\
\hline Geumnam Express & $\begin{array}{c}0.4832 * * \\
(25.71)\end{array}$ & $\begin{array}{c}0.4839 * * \\
(25.85)\end{array}$ & $\begin{array}{l}0.4838^{* *} \\
(25.81)\end{array}$ \\
\hline Hanyang Express & $\begin{array}{c}0.2989 * * \\
(23.24)\end{array}$ & $\begin{array}{l}0.3015^{* *} \\
(22.70)\end{array}$ & $\begin{array}{c}0.2993^{* *} \\
(23.21)\end{array}$ \\
\hline Jungbu Express & $\begin{array}{c}0.1724^{* *} \\
(10.12)\end{array}$ & $\begin{array}{c}0.1763 * * \\
(10.01)\end{array}$ & $\begin{array}{l}0.1722^{* *} \\
(10.02)\end{array}$ \\
\hline Samheung Express & $\begin{array}{c}0.3811^{* *} \\
(29.90)\end{array}$ & $\begin{array}{l}0.3804^{* *} \\
(29.67)\end{array}$ & $\begin{array}{l}0.3846^{* *} \\
(29.88)\end{array}$ \\
\hline \multicolumn{4}{|l|}{ Year } \\
\hline 2018 & $\begin{array}{c}0.0327^{\dagger} \\
(1.96)\end{array}$ & $\begin{array}{c}0.0341 * \\
(2.03)\end{array}$ & $\begin{array}{c}0.0323^{\dagger} \\
(1.93)\end{array}$ \\
\hline 2019 & $\begin{array}{l}0.0635^{* *} \\
(3.33)\end{array}$ & $\begin{array}{l}0.0644^{* * *} \\
(3.37)\end{array}$ & $\begin{array}{l}0.0636^{* *} \\
(3.34)\end{array}$ \\
\hline 2020 & $\begin{array}{c}-0.0744^{* *} \\
(-4.05)\end{array}$ & $\begin{array}{c}-0.0732 * * \\
(-3.97)\end{array}$ & $\begin{array}{l}0.0506 \\
(1.14)\end{array}$ \\
\hline Frequency in operation & $\begin{array}{c}0.0134^{* *} \\
(10.22)\end{array}$ & $\begin{array}{c}0.0135^{* *} \\
(10.20)\end{array}$ & $\begin{array}{c}0.0133^{* *} \\
(9.36)\end{array}$ \\
\hline Frequency in operation * 2020 & & & $\begin{array}{c}0.0011 \\
(0.39)\end{array}$ \\
\hline Operating distance & $\begin{array}{l}0.0017^{* *} \\
(3.90)\end{array}$ & $\begin{array}{c}0.0017^{* *} \\
(4.03)\end{array}$ & $\begin{array}{c}0.0018^{* *} \\
(4.36)\end{array}$ \\
\hline Operating distance * 2020 & & & $\begin{array}{c}-0.0008^{* *} \\
(-2.99)\end{array}$ \\
\hline Square of operating distance & $\begin{array}{c}-3.64 \times 10^{-6 * *} \\
(-3.35)\end{array}$ & $\begin{array}{c}-3.54 \times 10^{-6 * *} \\
(-3.24)\end{array}$ & $\begin{array}{c}-3.62 \times 10^{-6 * *} \\
(-3.35)\end{array}$ \\
\hline via Highway & $\begin{array}{l}-0.0064 \\
(-0.26)\end{array}$ & & $\begin{array}{l}-0.0015 \\
(-0.06)\end{array}$ \\
\hline Highway Toll & & $\begin{array}{c}-1.67 \times 10^{-6} \\
(-0.84)\end{array}$ & \\
\hline via Highway * 2020 & & & $\begin{array}{l}-0.0235 \\
(-0.39)\end{array}$ \\
\hline via capital region & $\begin{array}{l}-0.0067 \\
(-0.34)\end{array}$ & $\begin{array}{l}-0.0026 \\
(-0.15)\end{array}$ & $\begin{array}{l}-0.0106 \\
(-0.50)\end{array}$ \\
\hline via capital region * 2020 & & & $\begin{array}{c}0.0154 \\
(0.32)\end{array}$ \\
\hline Constant & $\begin{array}{l}-0.0207 \\
(-0.59)\end{array}$ & $\begin{array}{l}-0.0271 \\
(-0.76)\end{array}$ & $\begin{array}{l}-0.0496 \\
(-1.38)\end{array}$ \\
\hline Pseudo R-squared & 0.363 & 0.364 & 0.368 \\
\hline
\end{tabular}

Note. Numbers in parentheses are White-Huber's robust t-values. ${ }^{* *},{ }^{*}$, and ${ }^{+}$indicate statistical significance at $1 \%, 5 \%$, and $10 \%$ level, respectively. The number of observations (that is, bus lines) is 2508 , and 411 are right-censored.

When part of a line goes via a highway, it may increase the fuel efficiency-that is, the distance traveled at a given amount of fuel-and consequently improve the efficiency of the operation, but it also requires tolls when using the highway, which negatively affects the operational efficiency. Therefore, the operational efficiency in relation to whether the route operates via the highway or not is theoretically unclear. According to the analysis, the coefficients of variables indicating whether a route goes via the highway or not have negative estimates but are not statistically significant, which means that the opposite effects of fuel savings and toll costs are similar, offsetting each other.

Due to the greater population and economic activity in the capital region, the demand for intercity buses is relatively large for lines through the capital region, which might make them relatively efficient. However, the analysis results indicate that transfer lines including the capital region do not show a statistically significant higher efficiency. The final destination of most of the lines via the capital region is Incheon international airport. However, residents in the capital region have various options in the transportation to the 
airport, such as the subway, airport limousines, buses, taxis, and so on. Additionally, their fares are relatively low. Thus, even though the intercity bus operates via the capital region where the population density (that is, potential demand) is high, the efficiency of those lines is not relatively higher because the residents in the region do not use the intercity bus departing from Chungnam.

Column (3) in Table 2 represents the estimated effects of these variables on the operational efficiency when comparing the situations before and during the COVID-19 pandemic. This includes intersections with dummy variables representing the year 2020 for the frequency in operation, operating distance, highway use, and the capital region as additional explanatory variables. The frequency in operation, whether via highways or through the capital region, does not show a statistically significant change due to COVID-19. However, the difference in efficiency according to operating distance is significantly changed under the influence of COVID-19. Before COVID-19, efficiency increased by the economy of scale following an increase in operating distance-that is, the length of the line. However, in 2020, when COVID-19 spread in earnest, the size of this increase in efficiency caused by the economy of scale is relatively small. In the case of long-distance lines, the possibility of contracting COVID-19 will be higher because passengers spend more time in enclosed spaces shared with others. For this reason, it seems plausible to suggest that the intercity bus demand decreased due to the substitution of means of transportation such as using a personal vehicle during long-distance travel, and thus the efficiency of intercity bus operation reduced. Additionally, due to COVID-19 the overseas trips decreased drastically in 2020. Additionally, most routes to airports which were the long-distance ones with surplus before 2020 recorded deficit in 2020.

The data used in the empirical analysis of this paper correspond to panel data containing annual input variables and calculation variables for each intercity bus line. Thus, panel data analysis is possible, but dependent variables are censored to the right at the value of 1 . Theoretically, the value of the efficiency unit ranges between 0 and 1 . However, as seen in Table 1 , the minimum value of the efficiency unit is 0.003 rather than 0 . This means that left-censoring has not occurred. Therefore, we use the tobit model, which allows estimation of the random effect model for individual lines instead of the fixed effect model. Table A1 in the Appendix A shows the results estimated by the random effect model for the same regression equation as Table 2. A comparison makes it clear that the effects of individual variables on operational efficiency are not significantly different from the results in Table 2.

Table 3 shows the results of the analysis for each sample by dividing the entire sample into before COVID-19 - that is, from 2017 to 2019-and 2020, when the spread of COVID19 took place. In 2020, long-distance journeys-that is, traffic using lines with longer operating distances-undertaken by intercity buses were fewer in number than before, which is similar to the results presented in Table 2 for the entire sample but with cross terms and dummy variables for the year 2020. As mentioned, this reduction in intercity bus demand for long-distance travel is likely to be due to concerns about the close proximity to other passengers over a long period on intercity buses.

Table 3. Changes in factors affecting the efficiency of intercity bus operations due to COVID-19.

\begin{tabular}{|c|c|c|}
\hline & 2017-2019 & 2020 \\
\hline \multicolumn{3}{|l|}{ Intercity bus company } \\
\hline Geumnam Express & $\begin{array}{c}0.5120 * * \\
(24.87)\end{array}$ & $\begin{array}{c}0.3750^{* *} \\
(8.57)\end{array}$ \\
\hline Hanyang Express & $\begin{array}{c}0.3106^{* *} \\
(20.56)\end{array}$ & $\begin{array}{c}0.2603^{* *} \\
(11.15)\end{array}$ \\
\hline Jungbu Express & $\begin{array}{c}0.1677^{* * *} \\
(8.79)\end{array}$ & $\begin{array}{c}0.2202^{* *} \\
(6.04)\end{array}$ \\
\hline Samheung Express & $\begin{array}{c}0.3972 \text { ** } \\
(26.19)\end{array}$ & $\begin{array}{c}0.3395 \text { ** } \\
(14.79)\end{array}$ \\
\hline
\end{tabular}


Table 3. Cont.

\begin{tabular}{lcc}
\hline & $\mathbf{2 0 1 7 - 2 0 1 9}$ & 2020 \\
\hline Year & $0.0331^{*}$ & $(1.97)$ \\
2018 & $0.0633^{* *}$ & $0.0146^{* *}$ \\
2019 & $(3.30)$ & $(5.40)$ \\
& $0.0135^{* *}$ & 0.0005 \\
Frequency in operation & $(9.41)$ & $(0.62)$ \\
Operating distance & $0.0020^{* *}$ & $-2.14 \times 10^{-6}$ \\
Square of operating distance & $(4.11)$ & $(-1.20)$ \\
via Highway & $4.08 \times 10^{-6 * *}$ & -0.0007 \\
& $(-3.20)$ & $(-0.01)$ \\
via capital region & -0.0071 & -0.0010 \\
Constant term & $(-0.26)$ & $(-0.02)$ \\
& -0.0104 & 0.0683 \\
Number of observations & $(-0.48)$ & $(1.12)$ \\
Right-censored & $-0.0734^{\dagger}$ & 515 \\
Pseudo R-squared & $(-1.84)$ & 66 \\
\hline
\end{tabular}

Note. Numbers in parentheses are White-Huber's robust t-values. ${ }^{* *}, *$, and ${ }^{\dagger}$ indicates statistical significance at $1 \%, 5 \%$, and $10 \%$ level, respectively.

\section{Conclusions}

COVID-19 has caused many changes in daily life, and there have been major changes in the transportation sector, such as a sharp drop in traffic. This has undermined the efficiency of public transportation, including intercity buses. Considering that intercity buses rely heavily on (local) government budget support that needs to reflect the reduction in efficiency caused by COVID-19, which is an external shock, estimating the degree of efficiency reduction is important from both an academic and policy standpoint. Therefore, this paper estimates the operational efficiency of the entire intercity bus line system in Chungnam from 2017 to 2020 through data envelopment analysis and empirically analyzes the factors that affect it. In particular, it analyzes how efficiency decreased in 2020 due to COVID-19, and which characteristics of lines, such as the length of lines, frequency in operation, use of highways, and inclusion of the capital region, affect this efficiency through a tobit model.

The empirical results show that the efficiency of the operation of intercity bus lines in Chungnam was higher in 2018 and 2019 compared to 2017, but dramatically dropped in 2020 by $15.8 \%$. It appears that the efficiency is higher when a line operates more frequently and over a longer distance, but the efficiency increases at a decreasing rate as the operating distance becomes longer. Under the influence of COVID-19, the difference in efficiency according to operating distance seems to be statistically significant. On the contrary, the frequency in operation, whether via highways or through the capital region, did not show a statistically significant change in efficiency as a result of COVID-19.

One of our key findings is that there were economies of scale in the operating distancethat is, higher efficiency with longer distance of operation before 2020 but not in 2020. This may come from the fact that passengers' concerns regarding being infected by COVID-19 are relatively higher when riding a longer-distance line. Thus, after the outbreak of COVID-19, the demand for long-distance lines decreased drastically, and this affected the efficiency of bus companies negatively. Thus, a policy that reduces passengers' concerns would be helpful in recovering the efficiency. As policy tools, ventilating and sanitizing the inside of the long-distance bus in the middle of operation with regular stops, and the regulations that order passengers to wear masks, talk as little as possible, and eat no food need to be executed more strictly. 
Some papers (e.g., Nocera [20,21] and de Oña et al. [22], among others) deal with the method in assessing the quality of the public transport services. They imply that the transit quality needs to be taken into account when estimating the efficiency of the intercity bus operation. Unfortunately, this paper ignored this due to the limits on data.

Since DEA is a non-parametric approach, there exists a difficulty in interpreting the results. In particular, the estimates of parameters show only the direction of the effect of each independent variable instead of the degree to which the variables affect the efficiency.

As the determinants of the efficiency of intercity bus operation, the socio-demographic characteristics of the origins and the destinations of lines would be important, in particular, the extent to which the residents of the places where the line starts or ends are likely to switch from public transportation to private vehicles or vice versa in the case of the outbreak of an infectious disease, and how this would affect the ridership, fare revenues, and thus the efficiency of the public transportation. In addition, according to the purpose of trips (for example, commuting trip vs. shopping trip), the ridership of the public transportation would react differently to the external shock. These topics need to be addressed in the future.

Author Contributions: Conceptualization, W.K. and S.H.H.; methodology, W.K. and S.H.H.; software, S.H.H.; validation, W.K. and S.H.H.; resources, W.K.; data curation, W.K.; writing-original draft preparation, W.K. and S.H.H.; writing-review and editing, W.K. and S.H.H. Both authors have read and agreed to the published version of the manuscript.

Funding: This research was funded by Kongju National University, grant number 2018-0199.

Institutional Review Board Statement: Not applicable.

Informed Consent Statement: Not applicable.

Data Availability Statement: The data presented in this study are available on request from the corresponding author. The data are not publicly available due to privacy.

Acknowledgments: The authors would like to thank the three anonymous reviewers for their valuable comments and suggestions on previous versions of this paper.

Conflicts of Interest: The authors declare no conflict of interest.

\section{Appendix A}

Table A1. Tobit random effect model on factors affecting intercity bus operational efficiency.

\begin{tabular}{|c|c|c|c|}
\hline & (1) & (2) & (3) \\
\hline \multicolumn{4}{|l|}{ Intercity bus company } \\
\hline Geumnam Express & $\begin{array}{c}0.4749^{* *} \\
(22.29)\end{array}$ & $\begin{array}{c}0.4752 \text { ** } \\
(22.60)\end{array}$ & $\begin{array}{c}0.4751 \text { ** } \\
(22.33)\end{array}$ \\
\hline Hanyang Express & $\begin{array}{c}0.2976^{* *} \\
(10.42)\end{array}$ & $\begin{array}{c}0.2988^{* *} \\
(10.42)\end{array}$ & $\begin{array}{c}0.2981^{* *} \\
(10.46)\end{array}$ \\
\hline Jungbu Express & $\begin{array}{c}0.1721 \text { ** } \\
(5.56)\end{array}$ & $\begin{array}{c}0.1736 \text { ** } \\
(5.56)\end{array}$ & $\begin{array}{c}0.1712^{* *} \\
(5.55)\end{array}$ \\
\hline Samheung Express & $\begin{array}{c}0.3749 * * \\
(13.06)\end{array}$ & $\begin{array}{c}0.3745^{* *} \\
(13.03)\end{array}$ & $\begin{array}{c}0.3791 \text { ** } \\
(13.22)\end{array}$ \\
\hline \multicolumn{4}{|l|}{ Year } \\
\hline 2018 & $\begin{array}{c}0.0341 \text { * } \\
(2.48)\end{array}$ & $\begin{array}{c}0.0344 \text { * } \\
(2.50)\end{array}$ & $\begin{array}{c}0.0340 \text { * } \\
(2.48)\end{array}$ \\
\hline 2019 & $\begin{array}{c}0.0658^{* *} \\
(4.24)\end{array}$ & $\begin{array}{c}0.0660 * * \\
(4.25)\end{array}$ & $\begin{array}{c}0.0657^{* *} \\
(4.25)\end{array}$ \\
\hline 2020 & $\begin{array}{c}-0.0837^{* *} \\
(-5.21)\end{array}$ & $\begin{array}{c}-0.0834 \text { ** } \\
(-5.19)\end{array}$ & $\begin{array}{c}0.0203 \\
(0.52)\end{array}$ \\
\hline Frequency in operation & $\begin{array}{c}0.0122 * * \\
(12.28)\end{array}$ & $\begin{array}{c}0.0122 * * \\
(12.27)\end{array}$ & $\begin{array}{c}0.0121 \text { ** } \\
(12.02)\end{array}$ \\
\hline
\end{tabular}


Table A1. Cont.

\begin{tabular}{|c|c|c|c|}
\hline & (1) & (2) & (3) \\
\hline Frequency in operation * 2020 & & & $\begin{array}{l}0.0017 \\
(0.86)\end{array}$ \\
\hline Operating distance & $\begin{array}{c}0.0014^{* *} \\
(2.70)\end{array}$ & $\begin{array}{c}0.0014^{* *} \\
(2.75)\end{array}$ & $\begin{array}{c}0.0016^{* *} \\
(2.99)\end{array}$ \\
\hline Operating distance $* 2020$ & & & $\begin{array}{c}-0.0007 * * \\
(-2.83)\end{array}$ \\
\hline Square of operating distance & $\begin{array}{c}-3.13 \times 10^{-6 *} \\
(-2.39)\end{array}$ & $\begin{array}{c}-3.09 \times 10^{-6 *} \\
(-2.38)\end{array}$ & $\begin{array}{c}-3.13 \times 10^{-6 *} \\
(-2.40)\end{array}$ \\
\hline via Highway & $\begin{array}{l}-0.0021 \\
(-0.07)\end{array}$ & & $\begin{array}{l}0.0067 \\
(0.22)\end{array}$ \\
\hline Highway toll & & $\begin{array}{c}-7.11 \times 10^{-7} \\
(-0.30)\end{array}$ & \\
\hline via Highway * 2020 & & & $\begin{array}{l}-0.0442 \\
(-1.01)\end{array}$ \\
\hline via capital region & $\begin{array}{l}-0.0071 \\
(-0.30)\end{array}$ & $\begin{array}{l}-0.0049 \\
(-0.22)\end{array}$ & $\begin{array}{l}-0.0138 \\
(-0.57)\end{array}$ \\
\hline via capital region * 2020 & & & $\begin{array}{l}0.0312 \\
(0.92)\end{array}$ \\
\hline Constant term & $\begin{array}{l}0.0109 \\
(0.25)\end{array}$ & $\begin{array}{l}0.0081 \\
(0.18)\end{array}$ & $\begin{array}{l}-0.0155 \\
(-0.34)\end{array}$ \\
\hline log likelihood & -815.9 & -815.9 & -808.1 \\
\hline
\end{tabular}

Note. Numbers in parentheses are White-Huber's robust t-values. ${ }^{* *}$ and ${ }^{*}$ indicates statistical significance at $1 \%$ and $5 \%$ level, respectively. The number of observations (that is, bus lines) is 2508 , and 411 are right-censored.

\section{References}

1. Jang, D.I.; Im, S.H.; Sung, N.M. An analysis on impact of COVID-19 on transportation sector and policy response. Monthly Transp. 2020, 265, 5-16.

2. Sobieralski, J.B. COVID-19 and airline employment: Insights from historical uncertainty shocks to the industry. Transp. Res. Interdiscip. Perspect. 2020, 5, 100123. [CrossRef]

3. Jenelius, E.; Cebecauer, M. Impacts of COVID-19 on public transport ridership in Sweden: Analysis of ticket validations, sales and passenger counts. Transp. Res. Interdiscip. Perspect. 2020, 8, 100242.

4. Global Carbon Project. 2020. Available online: https://www.globalcarbonproject.org/carbonbudget/ (accessed on 15 March 2021).

5. Sung, W.Y.; Kang, J.H. An analysis on efficiency and influencing factors of the quasi-public bus operating system in Busan metropolitan city using DEA. J. Korea Contents Assoc. 2019, 19, 349-367.

6. Lee, C.H.; Na, J.M. A Study on the efficiency analysis of city bus routes with the implementation of bus quasi-public operation system: Focusing on Gwangju metropolitan city. Korean Reg. Dev. Assoc. 2016, 28, 199-216.

7. Oh, M.Y.; Kim, S.S. Analyzing efficiency in the Seoul's urban bus industry using data envelopment analysis. J. Korean Soc. Transp. 2002, 20, 59-68.

8. de Jong, G.; Cheung, F. Stochastic frontier models for public transport. In World Transport Research: Selected Proceedings of the 8th World Conference on Transport Research 1: Transport Models and Systems; Meersman, H., Van De Voore, E., Winkelmans, W., Eds.; Pergamon: New York, NY, USA, 1999; pp. 373-386.

9. Kumbhakar, S.; Bhattacharyya, A. Productivity growth in passenger-bus transportation: A heteroskedastic error component model with unbalanced panel data. Empir. Econ. 1996, 21, 557-573. [CrossRef]

10. Matas, A.; Raymond, J. Technical characteristics and efficiency of urban bus companies: The case of Spain. Transportation 1998, 25, 243-263. [CrossRef]

11. Sakano, R.; Obeng, K.; Azam, G. Subsidies and inefficiency: Stochastic frontier approach. Contemp. Econ. Policy 1997, 15, 113-127. [CrossRef]

12. Cui, Q.; He, L.; Liu, Y.; Zheng, Y.; Wei, W.; Yang, B.; Zhou, M. The impacts of COVID-19 pandemic on China's transport sectors based on the CGE model coupled with a decomposition analysis approach. Transp. Policy 2021, 103, 103-115. [CrossRef] [PubMed]

13. Loske, D. The impact of COVID-19 on transport volume and freight capacity dynamics: An empirical analysis in German food retail logistics. Transp. Res. Interdiscip. Perspect. 2020, 6, 100165. [CrossRef]

14. Hu, S.; Chen, P. Who left riding transit? Examining socioeconomic disparities in the impact of COVID-19 on ridership. Transp. Res. Part D Transp. Environ. 2021, 90, 102654. [CrossRef]

15. Peoples, J.; Abdullah, M.A.; Satar, N.M. COVID-19 and airline performance in the Asia Pacific region. Emerald Open Res. 2020, 2, 62. [CrossRef] 
16. Pereira, D.S.; de Mello, J.C.C.S. Efficiency evaluation of Brazilian airlines operations considering the Covid-19 outbreak. J. Air Transp. Manag. 2021, 91, 101976. [CrossRef] [PubMed]

17. Li, Q.; Bai, P.; Chen, Y.; Wei, X. Efficiency evaluation of bus transport operations given exogenous environmental factors. J. Adv. Transp. 2020, 8899782. [CrossRef]

18. Charnes, A.; Cooper, W.W.; Rhodes, E. Measuring the efficiency of decision making units. Eur. J. Oper. Res. 1978, 2, 429-444. [CrossRef]

19. Banker, R.D.; Charnes, A.; Cooper, W.W. Some models for estimating technical and scale inefficiencies in data envelopment analysis. Manag. Sci. 1984, 30, 1078-1092. [CrossRef]

20. Nocera, S. An operational approach for quality evaluation in public transport services. Ing. Ferrov. 2010, 65, 363-383.

21. Nocera, S. The key role of quality assessment in public transport policy. Traffic Eng. Control. 2011, 52, 394-398.

22. de Oña, J.; de Oña, R.; Eboli, L.; Mazzulla, G. Perceived service quality in bus transit service: A structural equation approach. Transp. Policy 2013, 29, 219-226. [CrossRef] 